\title{
Effect of different food recall strategies on consumers' reaction to different recall norms
}

\author{
A comparative study \\ Haiju $\mathrm{Hu}$ \\ Economics and Management School, Yanshan University, \\ Qinhuangdao, Hebei, China \\ Ramdane Djebarni \\ Business School, University of South Wales, Pontypridd, UK \\ Xiande Zhao \\ China Europe International Business School, Shanghai, China \\ Liwei Xiao \\ Business School, University of South Wales, Pontypridd, UK, and \\ Barbara Flynn \\ Kelley School of Business, Indiana University, Indianapolis, Indiana, USA
}

Food recall strategies

Received 31 October 2016 Revised 5 February 2017 Accepted 9 March 2017

\begin{abstract}
Purpose - Using the combined theoretical umbrella of organizational legitimacy theory, service-dominant logic, fairness heuristic theory and two-factor theory, the purpose of this paper is to investigate the effectiveness of different food recall strategies (recall proactiveness and compensation) in terms of both how consumers react (perceived organizational legitimacy and purchase intention) and how recall norms would influence the effectiveness in three countries. In addition to the reporting of important results, this paper provides implications for food companies to handle effectively the recalls, especially when the recalls are cross-country.

Design/methodology/approach - A 2 compensation (high vs low) $\times 2$ recall strategy (proactive vs passive) scenario experiment was conducted in Hong Kong, the USA and Mainland China. After checking the effectiveness of manipulation, the paper tested the main effect and interaction effect of recall proactiveness and compensation on perceived organizational legitimacy and purchase intention. In addition, the mediating effect of perceived organizational legitimacy between recall strategies and purchase intention was also tested. Findings - Significant main effect, interaction and mediation effect were found across the three countries with a different pattern. For the USA and Mainland China which have strong recall norms, the interaction found followed the predictions of the two-factory theory. However, the pattern found in Hong Kong, which has weak recall norms, followed the predictions of the fairness heuristic theory. Full mediation effect of perceived organizational legitimacy between compensation and purchase intention was found in the USA and Mainland China, while it was only partial in Hong Kong. For the mediation between proactiveness and purchase intention, full mediation was found in Hong Kong and the USA, while it was only partial in Mainland China.

Originality/value - First, this study differentiated food recall strategy into two dimensions - recall proactiveness and compensation. Second, this study tested the applicability of two-factor theory and fairness heuristic theory in recalls by testing the competing hypotheses proposed according to the two theories. Finally, this study can further help our understanding of the recall effectiveness across different recall norms. Keywords Product recalls, Organizational legitimacy, Fairness heuristic theory, Recall norms, Recall strategy, Two-factor theory

Paper type Research paper

(C) Haiju Hu, Ramdane Djebarni, Xiande Zhao, Liwei Xiao and Barbara Flynn. Published by Emerald Publishing Limited. This article is published under the Creative Commons Attribution (CC BY 4.0) licence. Anyone may reproduce, distribute, translate and create derivative works of this article (for both commercial \& non-commercial purposes), subject to full attribution to the original publication and authors. The full terms of this licence may be seen at http://creativecommons.org/licences/by/4.0/legalcode
\end{abstract}

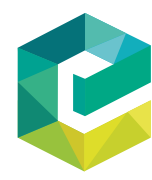

Industrial Management \& Data Systems Vol. 117 No. 9, 2017 pp. $2045-2063$ Emerald Publishing Limited 0263-5577 DOI 10.1108/IMDS-10-2016-0464 
IMDS

117,9

2046

\section{Introduction}

The sustainable success of manufacturing organizations has been and will continue to be, at least for a while, a backbone of the economic growth in developed, emerging and developing countries (Srinivasan, 2009).

Successful manufacturing organizations, all over the world, are under great pressure to implement several forward-thinking strategies in order to enhance their competitiveness and sustainability in the competitive global marketplace (Liu and Takala, 2010; Fuentes-Henríquez and Del Sol, 2012; Liu, 2013; Zhang et al., 2017).

One of these strategies is effective management of product recall as it helps enterprises not only to keep damage to a minimum but also ensure that brand reputation and customer loyalty are not affected in long term (Ni et al., 2016; Steven and Britto, 2016).

Product recall is a follow-up action of product-harm crisis and is defined as an action by a manufacturer or a distributor to remove a product from the market because it may cause health and/or safety problems and possibly death of consumers. Product recalls are increasing with product-harm crises due to the increasing complexity of products (Heerde et al., 2007), more complex global supply chains (Lyles et al., 2008), greater consumer awareness and more stringent product safety legislation (Dawar and Pillutla, 2000). As a case in a point in the food industry, the reinsurance company Swiss Re reported that in 2015, the number of US food products recalled, and the costs associated with those recalls, had nearly doubled since 2002 .

Product-harm crises and product recalls are recognized as one of a firm's worst nightmares (Van Heerde et al., 2007) since they frequently result in a decline of the stock price (Chen et al., 2009; Zhao and Flynn, 2013), denigrate carefully cultivated brand equity, tarnish a company's reputation (Cheah et al., 2007), increase sensitivity to rival firms' marketing activities (Van Heerde et al., 2007) and lead to loss in sales or even bankruptcy. In more than half of food recalls in the USA, the process of recalling the food cost the affected company more than $\$ 10$ million. Some companies lost more than $\$ 100$ million in direct costs associated with the recalls. Moreover, they trigger a chain effect throughout the supply chain and society as a whole (Dai et al., 2015).

In view of the negative effects stated above, the subject of product recalls has attracted more and more attention. An increasing number of scholars are engaged in this research area approaching the subject from different angles such as the impact of product-harm crisis and product recall on performance or brand image (Zhao et al., 2014), the operational factors that may lead to recalls (Steven and Britto, 2016) and design mechanisms to improve the supply chain traceability which will help the companies to prevent from recalls (Dai et al., 2015). Also, some scholars focused on the investigation of the effectiveness of recall strategies (Siomkos and Kurzbard, 1994; Smith et al., 1996; Chen et al., 2009; Hora et al., 2011; Claeys and Cauberghe, 2014) to help companies effectively handle recalls and reduce their negative effects.

Overall, previous studies attempted to test the effectiveness of recalls' strategy from two perspectives - firms' perspective and consumers' perspective.

From the firms' perspective, some researchers investigated how product recalls influence future performance of recall companies in terms of future product reliability and future accidents (Kalaignanam et al., 2013); on the other hand, some scholars tried to study the impact of different types of recalls on financial performance (in terms of stock price). For example, Chen et al. (2009) drew the conclusion that proactive strategies had a more negative effect on firms' value than passive strategies. Davidson and Worrell (1992) found evidence that the abnormal returns associated with recall announcements that replace the product or return the purchase price were more negative than those that announced a repair or check of a product. Ni et al. (2016) differentiated recall types by the initiators (producer, retailers or distributors) and found that stock market would react more negatively to recalls by retailer or distributors. This stream of studies was based on secondary data which were analyzed 
based on the assumption that people in the stock market will interpret different recall information as different related costs or potential profitability, and then will reflect this interpretation in their behavior in the stock market. Nevertheless, these studies cannot explain why people interpret different recalls as high or low cost.

From consumers' perspective, researchers strived to test the effectiveness of product recalls in terms of perceived danger or risk (Siomkos and Kurzbard, 1994; Wei et al., 2016), purchase intention (Siomkos and Kurzbard, 1994; Vassilikopoulou et al., 2009; Cleeren et al., 2013) and attitudes toward the company (Dean, 2004). These studies attempted to explain why product recalls bring losses to the focal company and why different recall strategies would have different effects. This stream of research, however, has its own limitations. First of all, those studies produced conflicting results, for instance, Mowen (1980) argued that consumers' intention to purchase was significantly influenced by the length of time the company took to decide to make the recall. However, Siomkos and Kurzbard (1994) found that the company's response (denial, involuntary recall, voluntary recall, super-effort) had no significant effect on perceived danger and future purchase intention. As a consequence, another group of researchers focused on the boundary condition of the recall strategy effectiveness, that is, the role moderator factors play, such as brand commitment (Germann et al., 2014) and corporate social responsibility (Hingley et al., 2013).

However, we argue that besides the contingent factors, such conflicting results may be due to researchers treating the recall strategy as one dimension, while actually, it has two decisions: when to recall is effected and how much consumers are compensated. Second, all the studies were carried out in Western countries and/or focused on one country only.

In view of the increasing number of product recalls in the world, especially the recall of the same product in different countries, research should be conducted to test how consumers from different countries react to different recalls strategies. This approach is very important since consumers' behaviors are culture or norms bound. To this effect, Kher et al. (2013) found that consumers from different countries ranked risks differently. It flows from this that consumers' reaction to recall strategies can differ from one country to another, and as a consequence, the effectiveness of the same recall strategy would vary from one country to another. Unfortunately, very few studies were carried out using such approach.

In view the limitations of the existing literature, this study intended to investigate the effects of food recall strategies on consumers' reaction by differentiating the two dimensions of a firm recall strategy (recall proactiveness and compensation). We used consumers perceived organizational legitimacy and purchase intention as the two dependent variables to reflect the effectiveness of recall strategies since legitimacy is very important for organizations to justify their actions and gain resources (Suchman, 1995) and purchase intention reflects the potential to generate profit after product recalls. Moreover, the research aimed to investigate the effect of recall norms in different countries.

In the following section, we first introduced service-dominant logic which was the basic logic used to guide us to study recalls from a service recovery perspective. Then the theoretical background to develop the hypotheses was provided. In Section 3, the experimental method we used to test the hypotheses was described. Section 4 presented the data analysis results and the last section served as the conclusion and discussion of this study.

\section{Theoretical background and research hypotheses}

\subsection{Service-dominate logic}

Service-dominate logic was first proposed by Vargo and Lusch (2004) in their work entitled "Evolving to a New Dominant Logic for Marketing." It had quickly attracted a lot of interest and it resulted in a rethink of the marketing logic paradigm.

Based on service-dominant logic, goods are distribution mechanisms for service provision (Lusch et al., 2007), that is, goods are a part of service. When the product is found 
IMDS 117,9

2048 to be defective, it is a kind of service failure, from which companies should take measures to recover (Zhao et al., 2014). Product recalls are remedy measures taken by companies to reduce the negative effect of product quality problems/product-harm crisis. According to service-dominant logic, it is a kind of service recovery, and hence we can investigate the product recalls effectiveness from service recovery perspective by employing the classical concept in service recovery - fairness.

Moreover, service-dominant logic is customer oriented (Lusch and Vargo, 2006). It emphasizes the importance of customers' perceptions because the main purpose of a company is to provide value for customers. Therefore, companies should focus not only on the provision of high-quality products but also on the whole life cycle of the product. For example, companies should provide superior after-sales service. Responsibilities of a company should not end up with the sale of the product. They should be extended to the end of usage of the product. Thus, when products are found defective, companies should take actions, such as recalls, to minimize the losses of consumers and maximize the value of the product which in turn will influence the perceptions of consumers.

\subsection{Organizational legitimacy}

Legitimacy is a social judgment that is ultimately accorded to an organization by its constituents (Ashforth, 1990). An organization will be perceived as legitimate when its value and actions are congruent with the audience's values and expectations for the action (Dowling and Pfeffer, 1975) or its audience accepts or endorses the organization's means and ends as valid, reasonable and rational (Suchman, 1995).

Suchman (1995) categorized legitimacy into three different types: pragmatic legitimacy, moral legitimacy and cognitive legitimacy. Pragmatic legitimacy rests on the self-interest calculations of an organization's immediate audience. Moral legitimacy rests on judgments on whether a given activity is "the right thing to do." In general, moral legitimacy takes one of the four forms: evaluations of outputs and consequences (consequential legitimacy), evaluations of techniques and procedures (procedural legitimacy), evaluations of categories and structures (structural legitimacy) and evaluations of leaders and representatives (personal legitimacy). Cognitive legitimacy is based on cognition and has two variants which are legitimacy based on comprehensibility and legitimacy based on "taken-for-grantedness."

Legitimacy is very important to organizations. First, legitimacy is an important resource (Perrow, 1970; Dowling and Pfeffer, 1975; Meyer and Rowan, 1977), since it can help attract economic resources and gain the social and political support necessary for their continued successful operations (Ogden and Clarke, 2005). Second, legitimacy affects not only how people act toward organizations, but also how they understand them (Suchman, 1995; Vergne, 2011). Audiences will perceive legitimate organizations as more worthy, more meaningful, more predictable and more trustworthy. Third, all kinds of organizational decisions require legitimation; otherwise, they cannot be justified.

The importance of organizational legitimacy in the operations management research, however, has been overlooked even though it has been studied for a long time in the marketing and management literature. In a product recall, it is very important that companies gain legitimacy of their decisions and reactions to product recalls. Therefore, in this study, we will use consumers' perceived legitimacy as a measure of the effectiveness of recall strategies.

\subsection{Main effect based on fairness in service recovery}

Although many studies had tested the effect of recall strategies as reviewed above, there is very little research, if any, that investigated the effect from a fairness perspective. In a service recovery, consumers expect to be treated fairly, both in process and outcome aspects (McColl-Kennedy and Sparks, 2003). Procedural fairness relates to how the authority will do in 
a service failure, while outcome fairness related to what the authority will do (Bianchi et al., 2015). In the process, consumers expect fairness in terms of policies, rules and timeliness of the process. For instance, if organizations can handle a service failure timely, consumers will perceive that the process is fair. Chen et al. (2009) differentiated between proactive and passive recalls: a proactive recall is one that is issued timely when a company becomes aware of a potential hazard through internal detection, even without any injury reported, while a passive recall entails delaying the recall process and/or shift the responsibility to other entities. It means that, from the fairness perspective in service recovery, proactive recalls will be perceived as more fair rather than passive recalls by consumers, even though investors interpret proactive recall as more financial loss according to by Chen et al. (2009). Consumers will perceive the outcome as fair if the outcome or compensations match the level of their dissatisfaction. In a product recall, consumers will endow the outcome fairness to the company if compensation matches the loss caused by the product defect.

Moreover, organizational legitimacy theory states that legitimacy is determined by the method of operation process and output of an organization (Dowling and Pfeffer, 1975). If an organization's process and output are congruent with the audience's expectations or accepted by the audience, legitimacy will be granted to the organization (Suchman, 1995). In a product recall, consumers perceive procedural and outcome fairness as just reflection of acceptance of recall process and output (that is proactiveness and compensation, respectively). Therefore, consumers will perceive the company as more legitimate, if the company can recall the defective product proactively and compensate more.

Based on the above, the following hypotheses are formulated:

H1a. Consumers will perceive the company that is proactive in recalls as more legitimate than one that is passive in recalls.

H2a. Consumers will perceive the company which compensates them more as more legitimate than one that compensates them less.

Moreover, the positive relationship between consumers attitudes and behaviors has been confirmed by several studies (Coombs, 2007; McDonald et al., 2010). A negative emotion will lead to negative behavior, while a positive emotion can increase the support for a company in a crisis, in terms of purchase intention (Coombs, 2007).

Undoubtedly, perceived fairness is a kind of positive attitude that consumers possess to an organization. When perceiving the procedural or outcome is fair, they will react as higher purchase intention. Choi and Choi (2014) also asserted that, in a service recovery, consumers will react positively to companies that meet their fairness expectations in terms of customer affection, loyalty and word-of-mouth. Moreover, Palmer et al. (2000) confirmed the direct effect of perceived fairness on repurchase intention in a service failure or recovery. Therefore, consumers will be more likely to purchase products from the recall company, which issues a proactive recall or offers a high compensation.

As a consequence of the above discussion, the following hypotheses are posited:

$H 1 b$. Consumers will have higher repurchase intention to companies that are proactive in recalls than those that are passive.

$H 2 b$. Consumers will have higher repurchase intention to companies which compensates them more than those that compensate them less.

\subsection{Interaction effect based on the two-factor theory}

The two-factor theory proposes that service attributes can be categorized into either qualifying or vantage factors of satisfaction. Usually, qualifying factors are those that consumers expect, while vantage factors are those that exceed over consumers' needs and

Food recall strategies 
IMDS

117,9

2050

expectations (Huang et al., 2015). Qualifying factors contribute to dissatisfaction if not met, while vantage factors contribute to satisfaction if met. Moreover, vantage factors affect satisfaction significantly only when qualifying factors meet or exceed consumer expectations (Johnston, 1995).

Huang et al. (2015) proposed that procedural fairness is a qualifying factor, since in service recovery, procedural fairness is often measured by response speed and consumers can easily form clear expectations of the time to deal with the failure, while the service provide has the minimum limitation to handle it. Therefore, in product recalls, recall proactiveness is a qualifying factor.

However, for compensation in a recall, this is not always necessary and expected, so recall companies can easily use this strategy to provide a service that exceeds consumers' expectations and satisfies them, which means the compensation is a vantage factor.

Therefore, and in accordance to the two-factor theory, one can predict that there will be a significant interaction effect between recall proactiveness and compensation, and hence the following hypotheses are formulated:

$H 3 a$. Compensation will not influence perceived legitimacy when the recall is passive, while compensation matters when the recall is proactive.

$H 3 b$. Compensation will not influence repurchase intention when the recall is passive, while compensation matters when the recall is proactive.

\subsection{Interaction effect based on fairness heuristic theory}

Many existing studies confirmed the interaction effect between procedure fairness and outcome fairness (e.g. Rolland and Steiner, 2007; Wu and Wu, 2015). Fairness heuristic theory explains the interaction effect that people use procedural fairness information to make inference about their relationship with the other party - in particular, how much to trust the other party (Lind, 2001). When people trust the exchange partner, the acceptance of the unfavorable outcome will increase; otherwise, the acceptance of the unfavorable outcome will decrease.

Thus, in recalls, consumers can use the information of recall proactiveness to make a judgment about whether the recall company is trustworthy. If the recall is proactive, consumers perceive the process as fair and consider the recall company as trustworthy. In this case, consumers will be more likely to accept a low compensation (unfavorable outcome to consumers) offered by the focal company which leads to uninfluenced perceived organizational legitimacy and repurchase intention by compensation. However, when the recall is passive, consumers will perceive the process as unfair and the focal company as untrustworthy. Then if the company offers a low compensation at this time, it will be hard for consumers to accept, and one can observe that their perceived organizational legitimacy and repurchase intention are significantly reduced over the high compensation condition.

Then according to fairness heuristic theory, we can predict the interaction pattern as follows:

$H 4 a$. Compensation will not influence perceived legitimacy when the recall is proactive, while compensation matters when the recall is passive.

$H 4 b$. Compensation will not influence perceived repurchase intention when the recall is proactive, while compensation matters when the recall is passive.

\subsection{Recall norms effect on the interaction pattern}

Based on previous studies related to fairness (e.g. Bos et al., 1996), expectations can influence the trust in the exchange company. Cadotte et al. (1987) affirm that norms are a critical determinant of consumers' expectations. 
In a weak recall norms condition, consumers do not have a clear expectation about the recall outcome. Then the process quality will be the primary determinant of trust in the company, which follows the pattern predicted by the fairness heuristic theory (Hui et al., 2004).

However, in a strong recall norms condition, consumers have a clear expectation about the outcome. When the norm is to give favorable outcome, violation of such norm does not only result in the unanticipated disappointment of consumers but also decreases the trust in the company. When the norm is to give unfavorable outcome, people will not trust in the company. In this case, the interaction will follow the pattern predicted by the two-factor theory.

In the USA and Mainland China, the recall norms are strong and consumers have a clear expectation how the recall will be handled since there are more recalls issued in these two countries. However, the norms are not the same: the USA has a long recall history dating back to 1966, a mature legal system, and most recalls are proactive.

The recall history in Mainland China, however, is short dating back to 2002 only, the legal system is considered immature, and most recalls are passive.

Compared with the above two countries, Hong Kong does not have a strong norm of recalls. Therefore, the expectation of consumers from Hong Kong is fuzzy, to say the least, while the Mainland China and the USA consumers have clear expectations about food recalls.

As a consequence of the above discussion, we propose the following hypotheses:

H5a. In Mainland China and the USA, the interaction pattern of recall proactiveness and compensation will follow the pattern predicted by two-factor theory.

$H 5 b$. In Hong Kong, the interaction pattern of recall proactiveness and compensation will follow the pattern predicted by fairness heuristic theory.

\subsection{Mediating effects of perceived organizational legitimacy}

Many psychology studies argue that emotions and attitudes are the central mechanism which can translate the fairness' perception into subsequent behavior (Schoefer and Diamantopoulos, 2008). These emotions and attitudes include trust, customer satisfaction, etc. To this effect, this argument had been confirmed by many studies in the area of service management research (cf. Su et al., 2016). Specifically, in the service recovery context, the results of a study by Schoefer and Diamantopoulos (2008) showed that emotions were a mediator of the relationship between perceived fairness and repurchase intention. Therefore, an organization's management activities can take effect to change consumers' behavior by affecting their emotions or attitudes.

Ogden and Clarke (2005) stress that legitimacy is an important resource which can help to gain economic resources and social support. Perceived organizational legitimacy is the attitude that an audience possesses to an organization. It also reflects the emotions of the consumer to the organization since people regard the legitimate organizations as more worthy, meaningful and trustworthy (Suchman, 1995; Vergne, 2011).

Therefore, we argue that perceived organizational legitimacy mediates the relationship between recall strategies and the repurchase intention of consumers, and consequently put forward the following hypotheses:

H6a. Perceived organizational legitimacy will mediate the relationship between compensation and repurchase intention.

H6b. Perceived organizational legitimacy will mediate the relationship between recall proactiveness and repurchase intention.

Figure 1 presents the conceptual model that was tested. 
IMDS

117,9

2052

Figure 1.

Experimental model

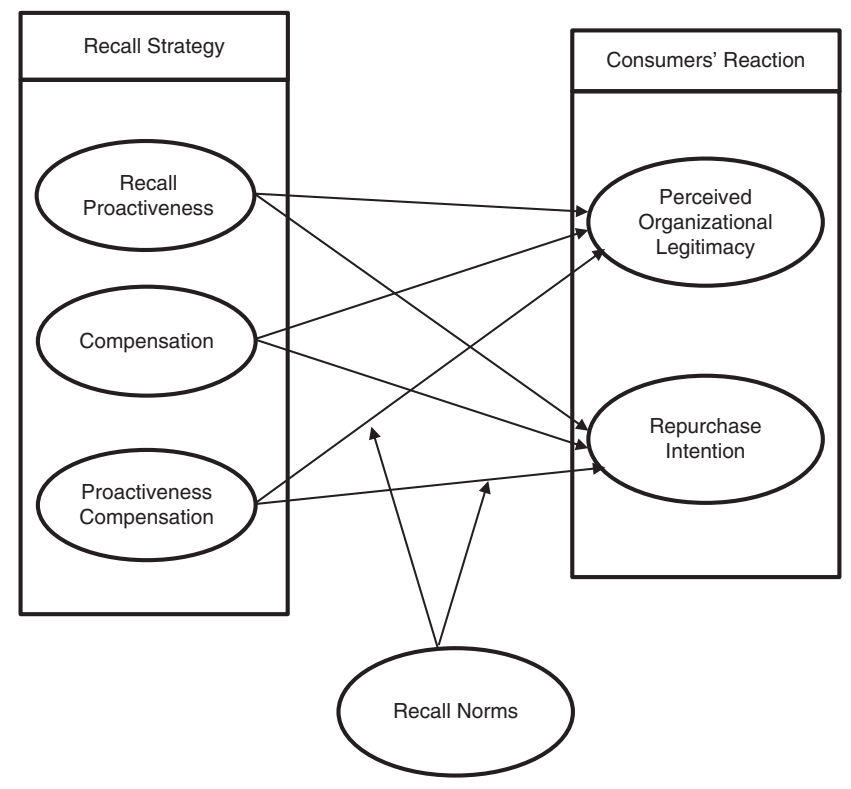

\section{Method}

The experimental methodology was employed to investigate the research question, because of its good internal validity to test the causality and it has been commonly used in service recovery and consumer behavior research (cf. Xu et al., 2014; Germann et al., 2014).

\subsection{Participants and experimental design}

A 2 compensation (high vs low) $\times 2$ recall strategy (proactive vs passive) scenario experiment was designed to test the hypothesis. In Mainland China, Hong Kong and the USA, we conducted the experiments using the same design. A total number of 423 students voluntarily participated in the experiment: 172 from Mainland China, 74 from Hong Kong and 177 from the USA.

To ensure participants' familiarity with the products, we chose a fruit juice company to contextualize the experiment. In addition, a fictional name (ABC) was used as the company's name in order to minimize possible subject bias.

\subsection{Procedure}

Questionnaires were administered to participants in classrooms. Before starting the experiment, the experimenter explained the procedures of the experiment emphasizing the issue of confidentiality and voluntariness. In the study, participants were asked to read carefully a short scenario as if it were real and then respond to a questionnaire. This experiment took around 15 minutes. After indicating their willingness to participate, the experimenter randomly distributed different scenarios and questionnaires among the participants.

In the first page of the questionnaire, there was a brief introduction similar to what the experimenter verbally instructed. Following that page, there was a one-page questionnaire where participants were asked questions on the frequency of drinking fruit juice, knowledge of product recalls and other demographic information. 
At the beginning of the scenario, respondents were provided with the background information about the company that included the following description:

Food recall strategies

Imagine that you are a consumer of the $\mathrm{ABC}$ group, a company which produces an orange juice drink. You have been drinking its juice drink for several years and really love it. Yesterday, $\mathrm{ABC}$ announced that it would recall 300,000 bottles of its orange juice drink (Production Code: 091206-01). The company reported that the additive used in these products was tainted due the company's production process and that consumption of the end products could lead to health problems.

Next, participants were shown the scenarios with either high or low compensation. The participants in the high compensation group were shown the following information:

$\mathrm{ABC}$ officially recalled the tainted products and offered a refund of five times the purchase price to all affected parties. In addition, ABC offered to cover the medical expenses for a physical check-up and any associated treatment.

Participants in the low compensation condition were shown the following: "ABC officially recalled the tainted products and offered a refund of the purchase price to all affected parties. No additional compensation was provided to the affected customers."

The participants were then shown the scenarios with either proactive or passive recall. In the proactive recall scenario, the company was described as follows: "A trusted media source reported that $\mathrm{ABC}$ found the defect through its own internal inspection and decided to recall the product immediately" for proactive calls. The passive recall condition included the following: "A trusted media source reported that $\mathrm{ABC}$ found the defect through its own internal inspection but didn't recall the products until ordered by the government to do so."

After reading the scenario, participants rated $\mathrm{ABC}$ on the company's response to product recalls and compensation as manipulation checks.

Finally, all the participants completed the questionnaire about their perceived organizational legitimacy and repurchase intention from $\mathrm{ABC}$.

\section{Analysis and results}

\subsection{Manipulation checks}

There were two manipulation checks, one for each independent variable.

Compensation manipulation check. The group means of perceived compensation are shown in Table I. For the three samples from different countries, participants in the high compensation group perceived that they were provided with higher compensation than in the low compensation group (Hong Kong: $F(1,63)=13.96, p<0.001$; the USA: $F(1,166)=59.45$, $p<0.001$; Mainland China: $F(1,161)=62.21, p<0.001)$. This perceived compensation was not affected by the company's recall proactiveness as illustrated in Table II. Therefore, the manipulation of compensation was successful. Moreover, we compared the group means across country with the same manipulation. The results showed that: in the low compensation group, the perception of compensation in Mainland China was lower than Hong Kong and the USA, but there was no difference between Hong Kong and the USA; and in the high compensation group, the perceived compensation was quite different with the USA as the highest, the Mainland China as the lowest and Hong Kong in the middle.

\begin{tabular}{llccc}
\hline Variables & Manipulations & Hong Kong & USA & Mainland China \\
\hline Perceived compensation & Compensation low & 3.17 & 3.18 & 2.32 \\
& Compensation high & 4.45 & 4.85 & 3.99 \\
Perceived proactiveness & Passive recall & 3.08 & 2.73 & 2.02 \\
& Proactive recall & 4.85 & 5.14 & 5.09
\end{tabular}

Table I. Group means 
IMDS 117,9

2054

Table II. $p$-value of univariate ANOVA for manipulation check
Recall proactiveness manipulation check. Participants in the proactive recall group regarded the response of the company much proactive than in the passive group (Hong Kong: $F(1,63)=27.86, p<0.001$; the USA: $F(1,166)=89.87, p<0.001$; Mainland China: $F(1,149)=255.39, p<0.001)$. This perceived response was not affected by the manipulation of compensation as shown in Table II. Therefore, the manipulation of company's recall proactiveness was successful. Moreover, we compared the group means of perceived proactiveness across countries with the same manipulation. The results showed that: in the passive recall group, the perception of proactiveness in Mainland China was lower than Hong Kong and the USA, but there was no difference between Hong Kong and the USA; and in the proactive recall group, there was no difference among the perceived proactiveness across the three countries.

\subsection{Test of hypotheses}

The data were analyzed using multivariate analysis of variance (MANOVA). MANOVA is more powerful for testing the effects when there is more than one dependent variable and these dependent variables are correlated with each other. The results presented in Table III show a significant multivariate main effect of compensation and recall proactiveness.

Moreover, in the univariate analysis, the perceived organizational legitimacy of participants in the proactive group was higher than that in the passive group (for Mainland China: proactive group: $M=4.23, \mathrm{SD}=1.17$; passive group: $M=3.56, \mathrm{SD}=1.02$; $F(1,154)=14.46, p<0.001)$. Therefore, $H 1 a$ was supported.

We also observed that for Mainland China consumers, the perceived organizational legitimacy in the high compensation group $(M=4.26, \mathrm{SD}=1.08)$ was significantly higher than that in the low compensation group $(M=3.54, \mathrm{SD}=1.11 ; F(1,154)=18.04, p<0.001)$. Thus, $H 2 a$ was supported.

\begin{tabular}{|c|c|c|c|c|c|c|}
\hline \multirow[b]{3}{*}{ IV } & \multicolumn{3}{|c|}{$\mathrm{DV}=$ perceived compensation } & \multicolumn{3}{|c|}{$\mathrm{DV}=$ perceived proactiveness } \\
\hline & Hong & & Mainland & Hong & & Mainland \\
\hline & Kong & USA & China & Kong & USA & China \\
\hline \multirow{3}{*}{$\begin{array}{l}\text { Compensation } \\
\text { Recall proactiveness } \\
\text { Compensation } \times \text { recall } \\
\text { proactiveness }\end{array}$} & 0.00 & 0.00 & 0.00 & 0.34 & 0.14 & 0.06 \\
\hline & 0.68 & 0.05 & 0.22 & 0.00 & 0.00 & 0.00 \\
\hline & 0.72 & 0.57 & 0.28 & 0.74 & 0.90 & 0.60 \\
\hline
\end{tabular}

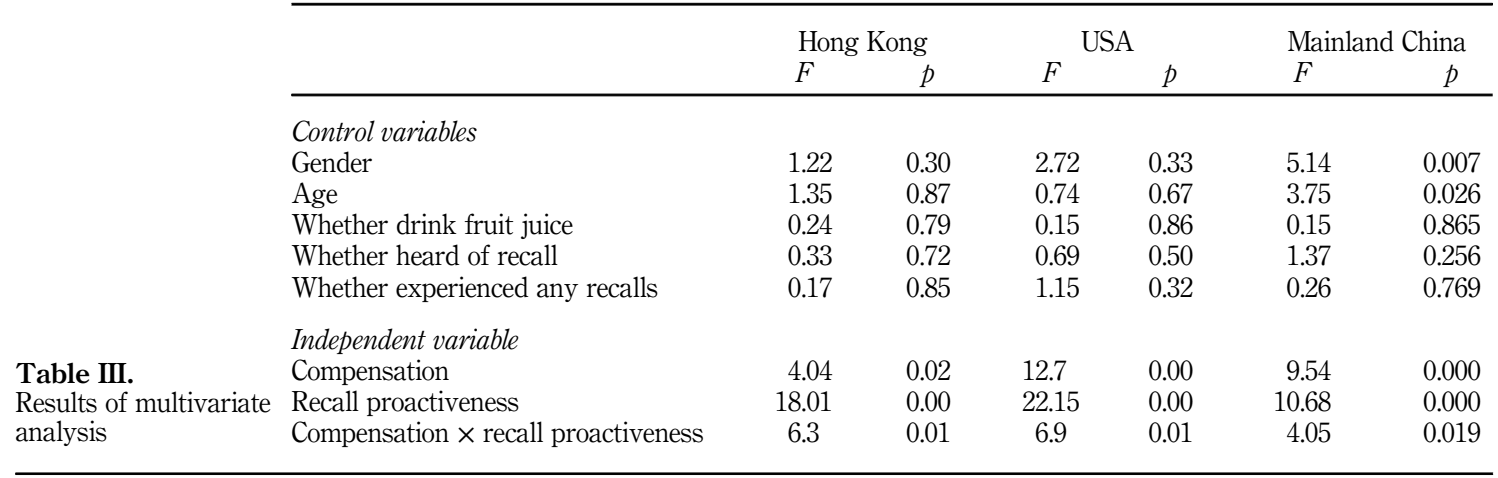


Both Hong Kong and the USA results supported the hypothesis as well. In addition, in the proactive group, the repurchase intention of participants was higher than that in the passive group (for Mainland China: proactive group: $M=3.71, \mathrm{SD}=1.56$; passive group: $M=2.78$, $\mathrm{SD}=1.30 ; F(1,154)=16.74, p<0.001)$. Therefore, $H 1 b$ was supported.

We also observed that the Mainland China repurchase intentions in the high compensation group $(M=3.59, \mathrm{SD}=1.49)$ was significantly higher than that in the low compensation group $(M=2.92, \mathrm{SD}=1.45 ; F(1,154)=8.33, p<0.01)$. Thus, $H 2 b$ was supported. In addition, we used the data from Hong Kong and the USA that can draw the same conclusion. The group means are listed in Table IV.

To test the interaction hypotheses, the simple main effect of compensation was tested in each level of recall proactiveness (as shown in Figures 2-4).

\begin{tabular}{|c|c|c|c|c|c|}
\hline $\mathrm{D}$ & IV & Hong Kong & USA & China & \\
\hline \multirow[t]{6}{*}{ Repurchase intention } & Compensation & & & & \\
\hline & Low & 2.32 & 3.04 & 2.58 & \\
\hline & High & 3.06 & 3.60 & 3.19 & \\
\hline & Proactiveness & & & & \\
\hline & Passive & 2.41 & 3.02 & 2.47 & \\
\hline & Proactive & 3.00 & 3.57 & 3.29 & \\
\hline \multirow{6}{*}{ Legitimacy } & Compensation & & & & \\
\hline & Low & 4.02 & 4.35 & 3.53 & \\
\hline & High & 4.59 & 4.71 & 4.26 & \\
\hline & Proactiveness & & & & Table IV. \\
\hline & Passive & 3.73 & 3.99 & 3.54 & Group means for \\
\hline & Proactive & 4.92 & 4.99 & 4.23 & main effect analysis \\
\hline
\end{tabular}

(a)

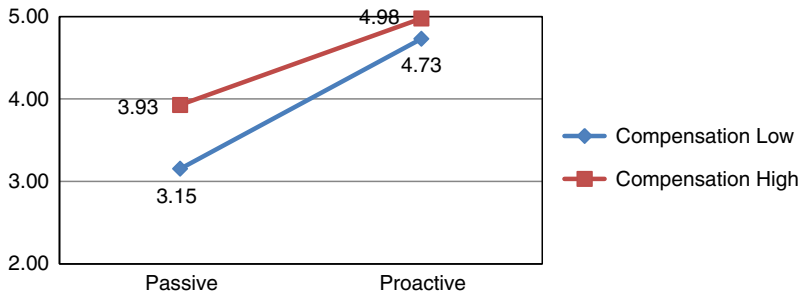

(b)

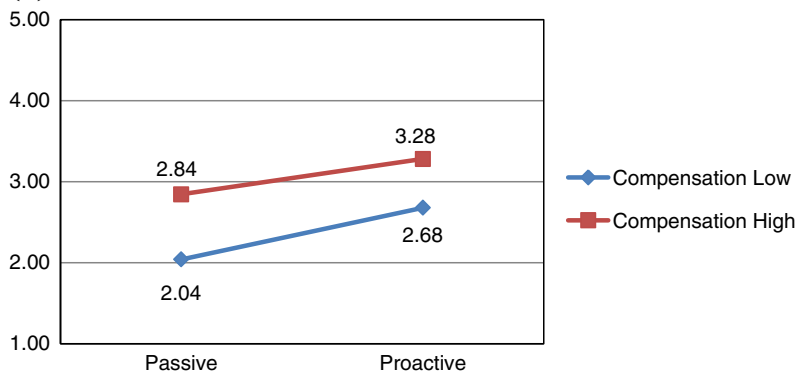

Notes: (a) Perceived organizational legitimacy; (b) repurchase intention
Food recall strategies

2055

Table IV. Group means for
Figure 2.

Interaction effect of Hong Kong sample 
IMDS

117,9

2056

Figure 3.

Interaction effect of the USA sample

Figure 4.

Interaction effect of the Mainland China sample

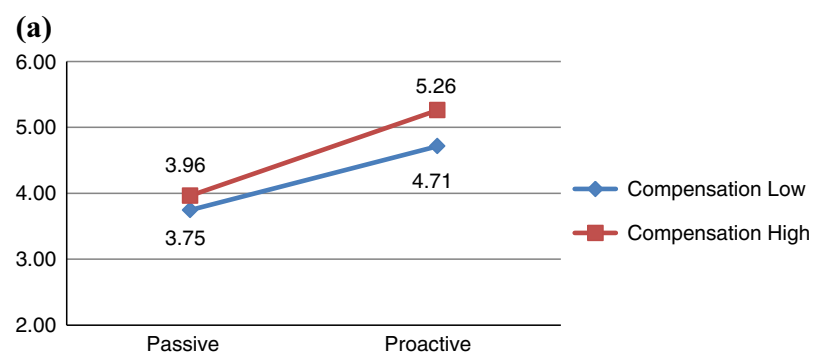

(b)

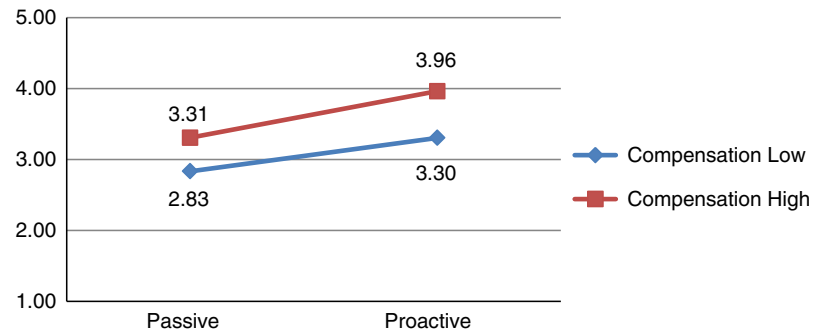

Notes: (a) Perceived organizational legitimacy; (b) repurchase intention

(a)

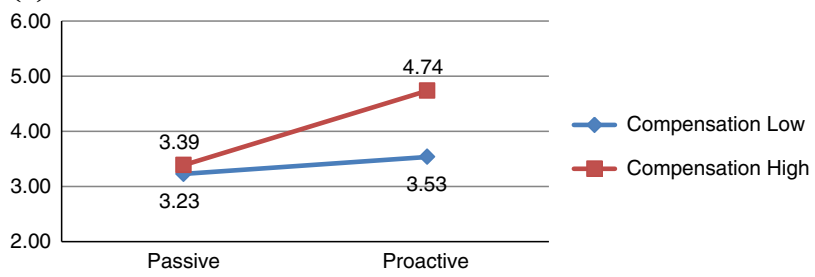

(b)

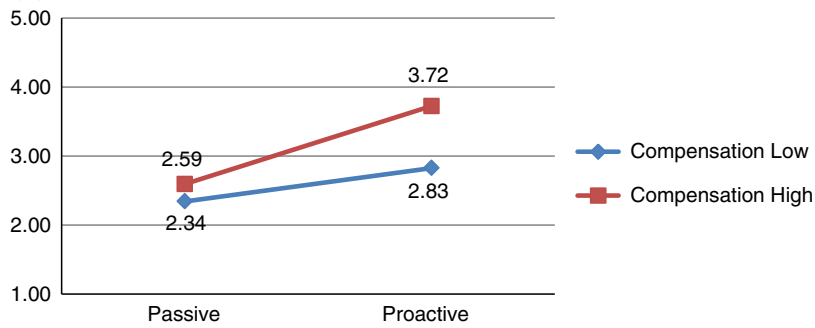

Notes: (a) Perceived organizational legitimacy; (b) repurchase intention

The results showed that when the company conducted a passive recall, the compensation level did not influence the perceived organizational legitimacy in the USA and Mainland China (for the USA: low compensation: $M=3.75$; high compensation: $M=3.96$; $F(1,89)=3.60, \quad p>0.1$; for Mainland China: low compensation $M=3.23$; high 
compensation: $M=3.39 ; F(1,81)=2.14, p>0.1)$; but in Hong Kong, compensation can increase perceived organizational legitimacy (low compensation $M=3.15$; high compensation: $M=3.93 ; F(1,36)=10.86, p<0.05)$. When the company conducted a proactive recall, the compensation level significantly improved purchase intension in the USA and Mainland China (for the USA: low compensation: $M=4.71$; high compensation: $M=5.26 ; F(1,89)=13.23, p<0.05$; for Mainland China: low compensation $M=3.53$; high compensation: $M=4.74 ; F(1,81)=1.01, p<0.001)$; but there was no difference in the case of Hong Kong (low compensation $M=4.73$; high compensation: $M=4.98 ; F(1,36)=1.32$, $p>0.1$. . Thus, the results supported the hypotheses about interaction effects. Both twofactor theory and fairness heuristic theory can be applicable in recalls. Specifically, data results from the USA and Mainland China supported the two-factor theory, while Hong Kong results supported the fairness heuristic theory. We, therefore, can conclude that $H 3 a$ was supported in the USA and Mainland China and $H 4 a$ was supported in Hong Kong.

Moreover, the results showed that when the company conducted a passive recall, the compensation level had no influence on the purchase intension in the USA and Mainland China (for the USA: low compensation: $M=2.83$; high compensation: $M=3.31 ; F$ $(1,81)=1.01, p>0.1$; for Mainland China: low compensation $M=2.34$; high compensation: $M=2.59 ; F(1,81)=1.01, p>0.1)$; but in Hong Kong, compensation increased purchase intention (low compensation $M=2.04$; high compensation: $M=2.84 ; F(1,81)=1.01$, $p<0.05)$. When the company conducted a proactive recall, the compensation level significantly improved purchase intension in the USA and Mainland China (for the USA: low compensation: $M=3.30$; high compensation: $M=3.96 ; F(1,81)=1.01, p<0.05$; for Mainland China: low compensation $M=2.83$; high compensation: $M=3.72 ; F(1,81)=1.01$, $p<0.005$ ); but in Hong Kong there was no difference (low compensation $M=2.68$; high compensation: $M=3.28 ; F(1,81)=1.01, p>0.1)$.

Similar to the results of the interaction effects on perceived organizational legitimacy, we also found the interaction effect on purchase intention. Specifically, the USA and Mainland China supported the two-factor theory, while Hong Kong supported the fairness heuristic theory. As a consequence, we can say that $H 3 b$ was supported in the USA and Mainland China and $H 4 b$ was supported in Hong Kong.

According to the above results, we can see that the interaction pattern in the USA and Mainland China followed the one that is predicted by two-factor theory, which supported $H 5 a$; however, the interaction pattern in Hong Kong followed the one predicted by fairness heuristic theory, which meant $H 5 b$ was supported.

Moreover, we tested the mediation effect of organizational legitimacy following the three steps proposed by Baron and Kenny (1986). The results are listed in Tables V and VI, from which we can concluded that perceived organizational legitimacy fully mediates the relationship between compensation and repurchase intention in the USA and Mainland China, while only partially mediate the relationship in Hong Kong. Therefore, H6a is supported in the USA and Mainland China and partially supported in Hong Kong.

\begin{tabular}{lccccccccc}
\hline & \multicolumn{3}{c}{ Hong Kong } & \multicolumn{3}{c}{ USA } & \multicolumn{3}{c}{ Mainland China } \\
& Model 1 & Model 2 & Model 3 & Model 1 & Model 2 & Model 3 & Model 1 & Model 2 & Model 3 \\
\hline Compensation & $0.25^{*}$ & $0.34^{* *}$ & $0.24^{*}$ & $0.16^{*}$ & $0.18^{*}$ & $0.09 \mathrm{~ns}$ & $0.30^{* * *}$ & $0.23^{* * *}$ & $0.06 \mathrm{~ns}$ \\
Legitimacy & - & - & $0.40^{* * *}$ & - & - & $0.57^{* * *}$ & - & - & $0.52^{* * *}$ \\
$R^{2}$ & $0.06^{*}$ & $0.12^{* * *}$ & $0.27^{* * *}$ & $0.03^{*}$ & $0.03^{*}$ & $0.35^{* * *}$ & $0.09^{* * *}$ & $0.05^{* *}$ & $0.35^{* * *}$ \\
$\Delta R^{2}$ & - & - & $0.15^{* * *}$ & - & - & $0.32^{* * *}$ & - & - & $0.29^{* * *}$
\end{tabular}

Notes: DV of model $1=$ legitimacy; DV of model $2=$ repurchase intention; DV of model $3=$ repurchase intention. ***,***Significant at $0.05,0.01$ and 0.005
Food recall strategies

2057
Table V.

Regression coefficients - mediating effect of perceived legitimacy between compensation and repurchase intention 
IMDS 117,9

\section{8}

Table VI.

Regression coefficients - mediating effect of perceived legitimacy between recall proactiveness and repurchase intention
As for the mediating effect of perceived organizational legitimacy between recall proactiveness and repurchase intention (in Table VI), a full mediating effect was found in the case of Hong Kong and the USA, while only partial mediation effect was found in the case of Mainland China. Therefore, H6b is supported in Hong Kong and the USA and partially supported in Mainland China.

\section{Conclusions and discussion}

\subsection{Findings}

In this study, we aimed to investigate the effectiveness of different food recall strategies from consumers' perspective, especially the effectiveness of the same recall strategy in different recall norms. Through experiments, we can draw the following conclusions.

First, significant main effects of compensation and recall proactiveness on purchase intention and perceived legitimacy indicate that both procedure and outcome have significant positive effect on consumers' attitudinal and behavioral reactions as expected by the service recovery perspective.

Second, there are significant interaction effect of recall proactiveness and compensation on purchase intention and perceived organizational legitimacy. However, in a different area, the interaction pattern will be different, which means that the effectiveness of the food recall strategy will be moderated by the recall norms.

Third, food recall strategies can influence consumers' purchase intention through perceived organizational legitimacy. However, in different areas, the mediation effect is a little different.

Finally, besides the above main findings, we also found that consumers from different areas treat the same recall strategy differently in the manipulation check, and we saw the different perceptions of the consumers on the same manipulation. This may be due to the recall norms in different areas, which made the consumer to have an expectation about how the company should handle recalls.

\subsection{Managerial implications and contributions}

As product recalls are becoming a common phenomenon, managers should think more about how to deal with the "nightmare" to reduce its negative effects and recover from the crisis. This is a difficult task for managers especially when the recall is cross-country. This study also provides some insights for managers to help them deal effectively with recalls.

First, to recover from the nightmare of food recalls more quickly, companies should provide a high compensation and make a proactive recall simultaneously. Without either one, the effectiveness of the other one will be discounted.

Second, consumers' attitude to a company plays a very importance role in consumers purchasing behavior to the recall company. Therefore, when a product recall happens, companies should take measures to keep consumers satisfied, which can be accomplished by both offering a good compensation and issuing a recall proactive.

\begin{tabular}{lcccccccccc}
\hline & \multicolumn{3}{c}{ Hong Kong } & \multicolumn{4}{c}{ USA } & \multicolumn{4}{c}{ Mainland China } \\
& Model 1 & Model 2 & Model 3 & Model 1 & Model 2 & Model 3 & Model 1 & Model 2 & Model 3 \\
\hline Proactiveness & $0.55^{* * * *}$ & $0.27^{*}$ & $0.04 \mathrm{~ns}$ & $0.46^{* * *}$ & $0.18^{*}$ & $-0.11 \mathrm{~ns}$ & $0.36^{* * *}$ & \multirow{2}{*}{$0.31^{* * *}$} & $0.16^{*}$ \\
Legitimacy & - & - & $0.44^{* * *}$ & - & - & $0.63^{* * *}$ & - & - & $0.49^{* * *}$ \\
$R^{2}$ & $0.31^{* * * *}$ & $0.07^{*}$ & $0.21^{* * *}$ & $0.21^{* * *}$ & $0.03^{*}$ & $0.35^{* * * *}$ & $0.13^{* * *}$ & $0.09^{* * *}$ & $0.31^{* * *}$ \\
$\Delta R^{2}$ & - & - & $0.14^{* * *}$ & - & - & $0.32^{* * *}$ & - & - & $0.22^{* * *}$
\end{tabular}

Notes: DV of model $1=$ legitimacy; DV of model $2=$ repurchase intention; DV of model $3=$ repurchase intention. *****significant at 0.05 and 0.005 
Third, the results of this study not only provide insights for food recalls but also have implications for recalls in other industry. The results highlighted the effect of recalls norms and cultural difference in cross-country recalls, which can be a significant determinate of recall strategy decisions. This is very important, as stressed by Liu (2013), for companies to gain sustainable competitive advantage, especially in the dynamic environment. It can help companies to think forward the management strategy of multinational recalls.

Fourth, companies should use the wealth of data that they have to manage recalls in line with the recommendation of Zhang et al. (2017) who advised that big data analytics can be used in connection with product life cycle. This will help in producing cleaner and safer products and help companies getting a sustainable competitive advantage.

Finally, for society, a good and effective recall strategy suggested by the current study will help reduce the negative perception and panic of consumers in product-harm crisis and change their attitude to recalls and the focal company, which will relieve the spillover effect of recalls. Recall as a kind of after-sales service and service recovery measure is also consistent with the core concept of cleaner production, which can be achieved by improving the after-sales service and managing the product life cycle (Zhang et al., 2017).

Theoretically, this study makes contributions by helping to explain the conflicting results on the effectiveness of different recall strategies by differentiated the two dimensions of recall strategies - recall proactiveness and compensation. Moreover, this study contributes to further our understanding of the effectiveness of recall strategy in different recall norms. By comparing the data collected from Hong Kong, the USA and Mainland China, we showed the applicability of the two-factor theory and fairness heuristic theory in recalls. In summary, this study contributes to provide more evidence on how consumers from different countries will react to company's different recall strategies and provide insights for companies to manage effectively their recall, especially for the ones that may issue a multinational recall.

\section{References}

Ashforth, B.E. (1990), “The double-edge of organizational legitimation”, Organization Science, Vol. 1 No. 2, pp. 177-194.

Baron, R.M. and Kenny, D.A. (1986), "The moderator-mediator variable distinction in social psychological research: conceptual, strategic, and statistical considerations", Journal of Personality and Social Psychology, Vol. 51 No. 6, pp. 1173-1182.

Bianchi, E.C., Brockner, J., van den Bos, K., Seifert, M., Moon, H., van Dijke, M. and De Cremer, D. (2015), "Trust in decision-making authorities dictates the form of the interactive relationship between outcome fairness and procedural fairness", Personality and Social Psychology Bulletin, Vol. 41 No. 1, pp. 19-34.

Bos, K., Vermunt, R. and Wilke, H.A. (1996), "The consistency rule and the voice effect: the influence of expectations on procedural fairness judgements and performance", European Journal of Social Psychology, Vol. 26 No. 3, pp. 411-428.

Cadotte, E.R., Woodruff, R.B. and Jenkins, R.L. (1987), "Expectations and norms in models of consumer satisfaction”, Journal of Marketing Research, Vol. 24 No. 3, pp. 305-314.

Cheah, E.T., Chan, W.L. and Chieng, C.L.L. (1987), "The corporate social responsibility of pharmaceutical product recalls: An empirical examination of US and UK Markets", Journal of Business Ethics, Vol. 76 No. 4, pp. 427-449.

Chen, Y., Ganesan, S. and Liu, Y. (2009), "Does a firm's product-recall strategy affect its financial value? An examination of strategic alternatives during product-harm crises", Journal of Marketing, Vol. 73 No. 6, pp. 214-226.

Choi, B. and Choi, B.J. (2014), "The effects of perceived service recovery justice on customer affection, loyalty, and word-of-mouth”, European Journal of Marketing, Vol. 48 Nos 1/2, pp. 108-131. 
IMDS 117,9

Claeys, A.S. and Cauberghe, V. (2014), "What makes crisis response strategies work? The impact of crisis involvement and message framing", Journal of Business Research, Vol. 67 No. 2, pp. 182-189.

Cleeren, K., van Heerde, H.J. and Dekimpe, M.G. (2013), "Rising from the ashes: how brands and categories can overcome product-harm crises”, Journal of Marketing, Vol. 77 No. 2, pp. 58-77.

Coombs, W.T. (2007), "Protecting organization reputation during a crisis: the development and application of situational crisis communication theory", Corporate Reputation Review, Vol. 10 No. 3, pp. 163-176.

Dai, H., Tseng, M.M. and Zipkin, P.H. (2015), "Design of traceability systems for product recall", International Journal of Production Research, Vol. 53 No. 2, pp. 511-531.

Davidson, W.N. and Worrell, D.L. (1992), "The Effect of Product Recall Announcements on Shareholder Wealth", Strategic management journal, Vol. 13 No. 6, pp. 467-473.

Dawar, N. and Pillutla, M. (2000), "Impact of product-harm crises on brand equity: the moderating role of consumer expectations", Journal of Marketing Research, Vol. 37 No. 2, pp. 215-226.

Dean, D. (2004), "Consumer reaction to negative publicity", Journal of Business Communication, Vol. 41 No. 2, pp. 192-211.

Dowling, J. and Pfeffer, J. (1975), "Organizational legitimacy: social values and organizational behavior”, Pacific Sociological Review, Vol. 18 No. 1, pp. 122-136.

Fuentes-Henríquez, F. and Del Sol, P. (2012), "Analogical foundation of the scope of organizational change", Journal of Organizational Change Management, Vol. 25 No. 1, pp. 163-185.

Germann, F., Grewal, R., Ross, W.T. Jr and Srivastava, R.K. (2014), "Product recalls and the moderating role of brand commitment", Marketing Letters, Vol. 25 No. 2, pp. 179-191.

Heerde, H.V., Helsen, K. and Dekimpe, M.G. (2007), "The impact of a product-harm crisis on marketing effectiveness", Marketing Science, Vol. 26 No. 2, pp. 230-245.

Hingley, M., Lindgreen, A., Reast, J., Assiouras, I., Ozgen, O. and Skourtis, G. (2013), "The impact of corporate social responsibility in food industry in product-harm crises", British Food Journal, Vol. 115 No. 1, pp. 108-123.

Hora, M., Bapuji, H. and Roth, A.V. (2011), "Safety hazard and time to recall: the role of recall strategy, product defect type, and supply chain player in the US toy industry", Journal of Operations Management, Vol. 29 Nos 7/8, pp. 766-777.

Huang, S.W., Hung, Y.W., Fu, T.W., Hsu, S.C. and Chiu, C.M. (2015), "Understanding the impact of service failure and recovery justice on consumers' satisfaction and repurchase intention", The Pacific Asia Conference on Information Systems.

Hui, M.K., Zhao, X., Fan, X. and Au, K. (2004), "When does the service process matter? A test of two competing theories”, Journal of Consumer Research, Vol. 31 No. 2, pp. 465-475.

Johnston, R. (1995), "The determinants of service quality: satisfiers and dissatisfiers", International Journal of Service Industry Management, Vol. 6 No. 5, pp. 53-71.

Kalaignanam, K., Kushwaha, T. and Eilert, M. (2013), "The impact of product recalls on future product reliability and future accidents: evidence from the automobile industry", Journal of Marketing, Vol. 77 No. 2, pp. 41-57.

Kher, S.V., De Jonge, J., Wentholt, M.T., Deliza, R., de Andrade, J.C., Cnossen, H.J. and Frewer, L.J. (2013), "Consumer perceptions of risks of chemical and microbiological contaminants associated with food chains: a cross-national study”, International Journal of Consumer Studies, Vol. 37 No. 1, pp. 73-83.

Lind, E.A. (2001), "Fairness heuristic theory: justice judgments as pivotal cognitions in organizational relations", in Greenberg, J. and Cropanzano, R. (Eds), Advances in Organizational Justice, Stanford University Press, Stanford, CA, pp. 56-88.

Liu, Y. (2013), "Sustainable competitive advantage in turbulent business environments", International Journal of Production Research, Vol. 51 No. 10, pp. 2821-2841.

Liu, Y. and Takala, J. (2010), "Competitiveness development of Chinese manufacturing enterprises in global context for crisis management", International Journal of Management and Enterprise Development, Vol. 9 No. 1, pp. 87-115. 
Lusch, R.F. and Vargo, S.L. (2006), "Service-dominant logic: reactions, reflections and refinements", Marketing Theory, Vol. 6 No. 3, pp. 281-288.

Lusch, R.F., Vargo, S.L. and O'Brien, M. (2007), "Competing through service: insights from servicedominant logic", Journal of Retailing, Vol. 83 No. 1, pp. 5-18.

Lyles, M.A., Flynn, B.B. and Frohlich, M.T. (2008), "All supply chains don't flow through: understanding supply chain issues in product recalls", Management and Organization Review, Vol. 4 No. 2, pp. 167-182, doi: 10.1111/j.1740-8784.2008.00106.x.

McColl-Kennedy, J.R. and Sparks, B.A. (2003), "Application of fairness theory to service failures and service recovery”, Journal of Service Research, Vol. 5 No. 3, pp. 251-266.

McDonald, L.M., Sparks, B. and Glendon, A.I. (2010), "Stakeholder reactions to company crisis communication and causes", Public Relations Review, Vol. 36 No. 3, pp. 263-271, doi: 10.1016/j. pubrev.2010.04.004.

Meyer, J.W. and Rowan, B. (1977), "Institutionalized organizations: formal structure as myth and ceremony", American Journal of Sociology, Vol. 83 No. 2, pp. 340-363.

Mowen, J. (1980), "Further information on consumer perceptions of product recalls", in Olson, J.C. (Ed.), NA - Advances in Consumer Research, Vol. 7, Association for Consumer Research, Ann Arbor, MI, pp. 519-523.

Ni, J., Flynn, B.B. and Jacobs, F.R. (2016), "The effect of a toy industry product recall announcement on shareholder wealth”, International Journal of Production Research, Vol. 54 No. 18, pp. 5404-5415.

Ogden, S. and Clarke, J. (2005), "Customer disclosures, impression management and the construction of legitimacy corporate reports in the UK privatised water industry", Accounting, Auditing and Accountability Journal, Vol. 18 No. 3, pp. 313-345.

Palmer, A., Beggs, R. and Keown, C.-M. (2000), "Equity and repurchase intention following service failure", Journal of Services Marketing, Vol. 14 No. 6, pp. 513-528.

Perrow, C. (1970), Organizational Analysis: A Sociological View, Wadsworth, OH.

Rolland, F. and Steiner, D.D. (2007), "Test-taker reactions to the selection process: effects of outcome favorability, explanations, and voice on fairness perceptions", Journal of Applied Social Psychology, Vol. 37 No. 12, pp. 2800-2826.

Schoefer, K. and Diamantopoulos, A. (2008), "The role of emotions in translating perceptions of (in) justice into postcomplaint behavioral responses", Journal of Service Research, Vol. 11 No. 1, pp. 91-103.

Siomkos, G. and Kurzbard, G. (1994), "The hidden crisis in product-harm crisis management", European Journal of Marketing, Vol. 28 No. 2, pp. 30-41.

Smith, N.C., Thomas, R.J. and Quelch, J.A. (1996), "A strategic approach to managing product recalls", Harvard Business Review, Vol. 74 No. 5, pp. 102-113.

Srinivasan, V. (2009), "Sustainable Manufacturing. Challenges to Innovation in Advanced Manufacturing: Industry Drivers and R\&D Needs", National Institute of Standards and Technology, Gaithersburg, available at: www.nist.gov/el/upload/whitepapers.pdf

Steven, A.B. and Britto, R.A. (2016), "Emerging market presence, inventory, and product recall linkages", Journal of Operations Management, Vol. 46 No. 1, pp. 55-68.

Su, L., Swanson, S.R. and Chen, X. (2016), "The impact of perceived service fairness and quality on the behavioral intentions of Chinese hotel guests: the mediating role of consumption emotions", Journal of Travel \& Tourism Marketing, Vol. 33 No. S1, pp. 88-102.

Suchman, M.C. (1995), "Managing legitimacy: strategic and institutional approaches", Academy of Management Review, Vol. 20 No. 3, pp. 571-610, doi: 10.5465/amr.1995.9508080331.

Van Heerde, H., Helsen, K. and Dekimpe, M. (2007), "The impact of a product-harm crisis on marketing effectiveness", Marketing Science, Vol. 26 No. 2, pp. 230-245, doi: 10.1287/mksc.1060.0227.

Vargo, S.L. and Lusch, R.F. (2004), "Evolving to a new dominant logic for marketing", Journal of Marketing, Vol. 68 No. 1, pp. 1-17. 
IMDS

117,9
Vassilikopoulou, A., Siomkos, G., Chatzipanagiotou, K. and Pantouvakis, A. (2009), "Product-harm crisis management: time heals all wounds?", Journal of Retailing \& Consumer Services, Vol. 16 No. 3, pp. 174-180.

Vergne, J.P. (2011), "Toward a new measure of organizational legitimacy: method, validation, and illustration”, Organizational Research Methods, Vol. 14 No. 3, pp. 484-502.

Wei, J., Zhao, M., Wang, F. and Zhao, D. (2016), "The effects of firm actions on customers' responses to product recall crises: analyzing an automobile recall in China", Journal of Risk Research, Vol. 19 No. 4, pp. 425-443.

Wu, X.N. and Wu, X. (2015), "Do the compensatory effects of outcome and procedure on policy acceptance depend on trust in authority?", Social Behavior and Personality, Vol. 43 No. 9, pp. 1429-1440.

Xu, Y., Marshall, R., Edvardsson, B. and Tronvoll, B. (2014), "Show you care: initiating co-creation in service recovery”, Journal of Service Management, Vol. 25 No. 3, pp. 369-387.

Zhang, Y., Ren, S., Liu, Y. and Si, S. (2017), "A big data analytics architecture for cleaner manufacturing and maintenance processes of complex products", Journal of Cleaner Production, Vol. 142 No. 2, pp. 626-641.

Zhao, X., Li, Y. and Flynn, B.B. (2013), "The financial impact of product recall announcements in China”, International Journal of Production Economics, Vol. 142 No. 1, pp. 115-123.

Zhao, X., Li, Y., Flynn, B.B. and Ng, S. (2014), "Impact of product recall announcements on shareholder wealth in China", Global Supply Chain Quality Management: Product Recalls and their Impact, Vol. 142 No. 1, pp. 197-217.

\section{Further reading}

Desai, P. and Patel, N. (2014), "Identifying backfire of communication on perceived hazard level during product recall", International Journal of Retailing and Rural Business Perspective, Vol. 3 No. 2, pp. 969-977.

Lin, C.P., Tsai, Y.H., Joe, S.W. and Chiu, C.K. (2013), "Modeling IT product recall intention based on the theory of reasoned action and information asymmetry: a qualitative aspect", Quality and Quantity, Vol. 47 No. 2, pp. 753-759.

Zhao, T.T. and Fan, X.C. (2014), "Product recalls as service failure: revisiting consumer reactions a conceptual framework", Proceedings 2014 International Conference on Service Sciences, pp. 226-228. 
Appendix

\begin{tabular}{ll} 
Construct & Items \\
\hline Recall strategy & What do you think about how ABC handles the recall? \\
& Extremely timely vs extremely delayed \\
Extremely passive vs extremely proactive \\
Compensation & What do you think about the ABC's compensation? \\
Purchase & Very little vs very large \\
intention & What is the chance for you to purchase orange juice from ABC in the future? \\
& Very unlikely vs very likely \\
Legitimacy inclined not to vs very inclined to & Certainly not vs certainly yes \\
& The way ABC handles the tainted orange juice is reasonable \\
& The way ABC handles the tainted orange juice is fair \\
ABC's managers are considerate of consumers \\
ABC has a strong sense of responsibility \\
ABC is an honest organization \\
ABC's compensation is reasonable \\
ABC's compensation is fair \\
I understand why ABC compensated its consumers' loss in this way \\
I understand why ABC responded to the internal inspection results at the speed that it did \\
The reason that ABC wanted to recall the tainted orange juice drink product is \\
understandable \\
The way that ABC recall the tainted orange juice is common in the industry \\
The way that ABC compensate consumers is common in the industry
\end{tabular}

\section{Corresponding author}

Ramdane Djebarni can be contacted at: rami.djebarni@southwales.ac.uk

For instructions on how to order reprints of this article, please visit our website: 